\title{
Transforming Academic Internationalization in Nursing Education in Ghana
}

Emmanuel Akwasi Marfo

University of Alberta, marfo@ualberta.ca

Desire Urindwanayo

University of Alberta, urindwan@ualberta.ca

Follow this and additional works at: https://qane-afı.casn.ca/journal

Part of the Nursing Commons

\section{Recommended Citation}

Marfo, Emmanuel Akwasi and Urindwanayo, Desire (2021) "Transforming Academic Internationalization in Nursing Education in Ghana," Quality Advancement in Nursing Education - Avancées en formation infirmière: Vol. 7: Iss. 1, Article 7.

DOI: https://doi.org/10.17483/2368-6669.1253

This International Perspective is brought to you for free and open access by Quality Advancement in Nursing Education Avancées en formation infirmière. It has been accepted for inclusion in Quality Advancement in Nursing Education - Avancées en formation infirmière by an authorized editor of Quality Advancement in Nursing Education - Avancées en formation infirmière. 


\section{Transforming Academic Internationalization in Nursing Education in Ghana}

\section{Cover Page Footnote}

We would like to acknowledge our appreciation for the assistance of Vivian Amoako Kyeremeh in reviewing this manuscript. Nous tenons à remercier Vivian Amoako Kyeremeh pour la révision de cet article. 


\section{Introduction}

The concepts of internationalization and globalization in higher education are used synonymously; however, they have different connotations (Altbach \& Knight, 2007). Academic internationalization is defined as "the process of integrating an international and intercultural dimension into the teaching, research, and service functions of the institution" (Knight, 2004, p. 9). On the other hand, globalization is centred on the inclusion of economic, sociocultural, and political fields in academia (Ergin \& Akin, 2017; Garone \& Van de Craen, 2017). The focus of globalization in higher education is to connect people and businesses around the world to higher learning institutions (Fox \& Hundley, 2011).

The impact of academic internationalization on higher learning institutions, countries of origin, and participants can be both positive and negative. In terms of positive benefits, academic internationalization promotes excellence in scholarship and fosters diversity in academic settings (Wit \& Hunter, 2014). The importance of internationalization and globalization in upholding global citizenship is exemplified in the ongoing academic diplomacy, interdisciplinary collaboration, and multiculturalism that exist in the various educational settings around the world (Nguyen et al., 2016).

Regardless of these intended goals of academic internationalization, it is worth acknowledging that most participating less-resourced countries face a loss of human resources because of "brain drain" (Mlambo et al., 2020). For instance, of the temporary residents who entered Canada between 1990 and 2014 with study permits, over 270,000 became permanent residents by 2014 (Lu \& Hou, 2015), thereby generating a loss of human capital to their respective countries. Reflecting on our lived experiences as international graduate students, we remind ourselves of the social, psychological, and emotional challenges that some international students and faculty may endure while attempting to integrate into their host environments. These challenges may potentially have a destructive impact on participating faculty and students' physical and mental health.

Despite these potential limitations, academic internationalization continues to hold a high value within the academic discourse community and the world of work. An institution's academic internationalization engagement is considered a major criterion for global university rankings by several institutions. Higher university rankings are associated with a good global reputation, funding, attractiveness to students, and industry partnerships (Hazelkorn, 2009). These internationalization activities in the academy are reflected in faculty research collaboration and publications, and international student exchange programs.

Through bilateral and multilateral institutional partnerships as well as continental and international nursing organizations, some of the 218 accredited nursing schools in Ghana engage in nursing academic internationalization to some extent. This paper aims to discuss how academic internationalization has influenced the development of Ghanaian nursing education. To accomplish this, we will reflect on the history of the internationalization with regard to nursing education in Ghana and briefly discuss such international activities' outcomes. We will also highlight the positive impacts of academic internationalization on Ghanaian nursing education. Finally, we will explore and discuss some aspects of academic internationalization in the Ghanaian nursing education program that need to be transformed. In this paper, a Ghanaian university nursing program is used as a case study inasmuch as there appears to be limited documentation on the international activities of most nursing schools in Ghana. 


\section{Historical Influence of Internationalization in Ghanaian Nursing Education}

In pre-colonial Ghana, herbalists and patients' relatives provided care whenever someone fell sick (Adu-Gyamfi \& Brenya, 2016). The health care patterns, processes, and delivery have changed to some extent over time with the introduction of Western-style medicine. The introduction of Western-style medicine in 1878 resulted in male orderlies enrolling in nursing apprenticeships to provide basic care (Adu-Gyamfi \& Brenya, 2016). The arrival of British nursing sisters in Ghana in 1899 significantly raised a nationwide pursuit of nursing practice by females (Donkor \& Andrews, 2011). The need for standardized education for nurses became imperative in the early 1940s, and two basic nursing programs, the state registered nurse and qualified registered nurse, were established under the Nurses' Ordinance Act of 1946 by the British Colonial Government (Kisseih, 1962). Seventeen years later, the Ghanaian university introduced the first diploma nursing program with support from the World Health Organization, the Government of Ghana, and the United Nations International Children's Education Fund (Opare \& Mill, 2000). In 1980, the Ghanaian university introduced a Bachelor of Arts or Science degree in nursing to prepare nurses to occupy leadership and administrative roles (Aziato \& Kwashie, 2014).

Following this process, the limited ability to recruit the graduate-prepared nurses required to occupy faculty and leadership positions for the Ghanaian university and other nursing institutions created a challenge for the Ghanaian government (Ogilvie et al., 2005). The need to establish a master's program for nurses at the Ghanaian university for nurses became vital. Through a collaboration between the nursing faculty from the Ghanaian university and the nursing faculty from a Western Canadian University, a master of philosophy (MPhil) in nursing was implemented at the Ghanaian university in 1999, with funding from the Canadian International Development Agency through the Canadian Association of Colleges and Universities (Ogilvie et al., 2003).

In the early 2000s, more undergraduate nursing programs were introduced into both private and state-funded institutions across Ghana (Aziato \& Kwashie, 2014). Currently, the School of Nursing's engagement in international activities at the Ghanaian university is demonstrated through hosting undergraduate nursing students from the Canadian university for a community health nursing practicum, and the Ghanaian university sending graduate students to the Canadian university for exchange programs and faculty for postdoctoral fellowships. Through collaboration with other departments at the Ghanaian university and support from the Faculty of Nursing at the Canadian university, the Ghanaian university has the only doctoral nursing program in Ghana (School of Nursing and Midwifery, n.d.-a).

One of the most impactful internationalization programs in Ghanaian nursing education history is the partnership between the Ghanaian university and the Western Canadian university in establishing the MPhil nursing program at the Ghanaian university (Astle, 2008). According to Aziato and Kwashie (2014), 62 students had graduated from the MPhil program by 2013 and occupied several teaching and administrative positions across the country. Additionally, the sustained production of nurse educators from the MPhil program at the Ghanaian university has indirectly contributed to an increase in nursing students' enrollments. Expanding nursing preparatory institutions and maximizing students' enrollment has a long-term benefit for addressing nursing staff shortages. With regard to the Canadians, Ghana continues to host their undergraduate students for community nursing practica. This international collaboration has also provided opportunities for both institutions to further develop their experiences in establishing international programs even though most of the Canadian professors had already had considerable 
international experience (Ogilvie et al., 2003). This brief historical reflection underscores the impact of academic internationalization on the development of nursing education in Ghana.

\section{Positive Aspects of Internationalization of Nursing Education in Ghana}

Many aspects of the internationalization of nursing education in Ghana are positive, including international student exchange programs, inter-faculty doctoral fellowships, graduate thesis co-supervision, and inter-faculty co-publication between faculty from the Canadian university and the Ghanaian university. These international initiatives can stimulate creativity and innovation among students and faculty (Jibeen \& Khan, 2015). International nursing exchange programs can create cultural awareness among students and expose them to intercultural sensitivities (Kelleher, 2013). Inter-faculty research and co-publication can encourage the development of global nursing knowledge about health and nursing education. For example, through the collaboration between faculty from the Canadian university and the Ghanaian university in building capacity for nursing education in Ghana, it emerged that "mutual trust, tolerance of ambiguity, and a willingness to step into the unknown" were necessary for international programs involving two or more schools (Ogilvie et al., 2003, p. 113).

The introduction of French language and sign language into the undergraduate curricula is a new aspect of academic internationalization in nursing education across Ghana by the Nursing and Midwifery Council of Ghana (2018). We believe that such an initiative towards multilingualism in nursing education can reinforce Ghana's capacity for hosting refugees from neighbouring war-torn countries, most of which are French-speaking. Existing literature suggests that effective communication is crucial for therapeutic nurse-patient relationships and efficient patient care (Huisman-de Waal et al., 2018). Therefore, it is salient to uphold the integration of French and sign language in Ghanaian nursing education. French language and sign-language literacy can facilitate interactions between graduate nurses and patients from different linguistic backgrounds.

\section{The Aspects of Internationalization in Ghanaian Nursing Education that Require Transformation}

The focus of nursing education and health care delivery worldwide appears to be shifting towards globalization because of emerging market economies and political alliances from neoliberal perspectives (Myrick, 2004). The universal shift towards globalization is reflected in the mission statement of the School of Nursing and Midwifery (n.d.-b) at the Ghanaian university: "to produce world-class nurses and midwives with the requisite knowledge and skills to provide services to individuals, families, and communities, and generate knowledge through research to improve nursing and midwifery practice." However, certain aspects of the Ghanaian university's nursing program can be described as limited with respect to academic internationalization and therefore require transformation.

First, the policy governing the collaboration between the two institutions should be reviewed to reflect mutual respect and benefit. The Ghanaian university students who visit the Canadian university for international exchange programs have limited rights to experience clinical learning. Despite international students, including those from Ghana, constituting about 22\% of the graduate student population at the Canadian university (S. Richter, personal communication, October 29, 2019), they do not have access to clinical learning. This issue appears to be a widely known problem of which some stakeholders may be aware. However, the knowledge of these imbalanced learning experiences for international students at the Canadian university can be 
considered anecdotal as there appears to be no accessible literature examining the learning experiences of those international students after visiting the Canadian university. For instance, undergraduate students from the Canadian university are permitted to freely engage with patients in hospitals and their communities when they visit Ghana. However, Ghanaian university students are denied those learning opportunities when they visit Canada. This kind of cooperation mirrors skewed power dynamics between Western and low-/middle-income countries during international collaborations (Adams et al., 2016). As a result, Canadian university students may acquire more learning experiences than their Ghanaian counterparts.

Also, the Ghanaian program coordinators seem to be interested in research experiences only for their graduate students. However, we are of the view that the choice for clinical or research experience during international exchange programs should not be bound to faculty interests and policies, as both experiences (clinical and research) can offer fertile grounds for collaborative learning and knowledge sharing. While acknowledging the differences in professional nursing regulation between the two countries, we suggest that the coordinators of the exchange program ensure that participating students from both partnering institutions enjoy equal learning opportunities. The Canadian university does not deliberately intend to exempt its international students from learning and working in clinical settings in the province, although it is compelled by the provincial nursing regulatory body to do so to ensure patient and public safety (S. Richter, personal communication, October 29, 2019). This restriction is not particular to this Canadian university but occurs across all provincial and foreign jurisdictions and is intended to ensure that internationally educated nurses are competent to provide culturally safe care (Viken et al., 2018). This is consistent with the World Health Organization's proposal that internationally educated nurses are offered orientation programs to operate safely and effectively in foreign jurisdictions (World Health Organization, 2010). Based on this analysis, we call on the Ghanaian coordinators to initiate strategic stakeholder consultations, including with provincial nursing regulatory boards and academic institutions, to develop orientation programs for international students so that they can gain access to clinical learning sites.

Additionally, curriculum developers for the nursing program at the Ghanaian university should consider introducing courses that focus on global and immigrant health. Owing to the increased migration across international borders in contemporary times, nursing school programmers are required to focus on health issues characteristic not only of the country or the sub-region but also globally (Wilson et al., 2012). Since nurses are among the essential workers relied on during international crises (Al Thobaity \& Alshammari, 2020), the Ghanaian curriculum developers could consider revising the curriculum to include content on health care responses to regional epidemics, pandemics, and global emergencies such as terrorism and warfare. These skill sets are consistent with the emerging roles of the professional nurse. Furthermore, the recent export of Ghanaian nurses to Barbados by the Government of Ghana (Lippke, 2020) and the migration of nurses from Ghana to the United Kingdom (Quartey \& Kwakye, 2009) reaffirms the need for curriculum revision to reflect international and global concepts of health care delivery. Ghanaian curriculum developers can achieve an internationalized curriculum by exposing students to social determinants of migrant health, cultural safety, and concepts of diversity and inclusion in healthcare delivery. Wilson et al. (2012) recommended incorporating key concepts of global health equity, social justice, determinants of health, and global citizenship to broaden the international acuity of undergraduate nurses. Consequently, students may develop interests in global volunteerism, public health, and cultural safety while working abroad or caring for migrants at home (Holmes et al., 2012). 
Another critical consideration for academic internationalization is to internationalize the Ghanaian academic faculty (Bedenlier \& Zawacki-Richter, 2012). How can faculty without international experience appropriately incorporate global perspectives into teaching and learning? We do not imply that faculty without international backgrounds cannot facilitate academic internationalization activities. However, similar to involving international students, we strongly believe that recruiting and retaining tenure-track and non-tenured faculty from diverse national and educational backgrounds has great potential to advance academic internationalization. This is because faculty members with international backgrounds can bring their lived global experiences to the teaching and learning initiative.

Last, although the concept of academic internationalization is usually viewed at the national level, Agnew and Duffie VanBalkom (2009) highlighted leadership and interdisciplinary knowledge transfer as key components to its success. Unfortunately, the Ghanaian university's undergraduate nursing program echoes the traditional medical-centred nursing education model (Bevis \& Watson, 1989), with minimal focus on leadership and interdisciplinary learning. This approach is evident in the program's course structure and sequence in which topics on medical and surgical conditions are deconstructed and delivered over multiple years separately from nursing content. Specific examples of such courses include medical conditions of the integumentary, gastrointestinal, and endocrine systems; obstetric anatomy and normal pregnancy; and medical and surgical conditions of the newborn, among others. We recognize the significance of these biomedical courses and the inclination to teach them as they serve as the foundations of most clinical intervention nurses perform. However, to prepare nurses who can influence policy and advance the nursing profession's image and interest at local and global levels, it is crucial to expose them to principles of change, leadership, informatics, and interdisciplinary learning. We, therefore, call for maintenance of these courses but request that curriculum developers at the Ghanaian university structure and sequence these biomedical courses seamlessly to allow for the inclusion of more content on leadership and interdisciplinary education. We contend that such courses can equip students with the creative and innovative skills required to spearhead both local and global health intervention and implementation programs (Weberg \& Weberg, 2014). Interdisciplinary education can equip undergraduate nurses with the knowledge of practice and professional perspectives of other health teams (Donato et al., 2016). Consequently, this approach can facilitate teamwork and collaborative health knowledge inquiry and translation across diverse health care settings (Donato et al., 2016).

\section{Conclusion}

This paper relays possible shortcomings in academic collaborations between international universities, both those in the process of development and established ones, which in turn can help transform existing policies to reflect the intended goals for which such academic internationalization activities are conducted. The international relationship between the Canadian university and Ghanaian university continues to impact Ghanaian nursing education to a profound extent. Through the exchange programs between the collaborating institutions, students broaden their knowledge of different cultures, which is relevant to working at the global level. However, certain aspects of this international partnership are not without their limitations and, hence, require transformation. There is a need to revise the policy that guides this international program partnership to ensure equal benefits for participating students. We argued that the Ghanaian university needs to undertake a curriculum revision to integrate courses on interdisciplinary education and team-centric leadership for undergraduate students. Interdisciplinary education will 
Quality Advancement in Nursing Education - Avancées en formation infirmière, Vol. 7, Iss. 1 [2021], Art. 7

expose nursing students to other health disciplines' values and beliefs, thereby fostering more collaboration when nurses are working on the international scene. 


\section{References}

Adams, L. V., Wagner, C. M., Nutt, C. T., \& Binagwaho, A. (2016). The future of global health education: Training for equity in global health. BMC Medical Education, 16(1), 296-297. https://doi.org/10.1186/s12909-016-0820-0

Adu-Gyamfi, S., \& Brenya, E. (2016). Nursing in Ghana: A search for Florence Nightingale in an African city. International Scholarly Research Notices, 2016, 1-14. https://doi.org/10.1155/2016/9754845

Agnew, M., \& Duffie VanBalkom, W. (2009). Internationalization of the university: factors impacting cultural readiness for organizational change. Intercultural Education, 20(5), 451-462. https://doi.org/10.1080/14675980903371324

Altbach, P. G., \& Knight, J. (2007). The internationalization of higher education: Motivations and realities. Journal of Studies in International Education, 11(3-4), 290-305. https://doi.org/10.1177/1028315307303542

Al Thobaity, A., \& Alshammari, F. (2020). Nurses on the frontline against the COVID-19 pandemic: An integrative review. Dubai Medical Journal, 3(87), 87-92. https://doi.org/10.1159/000509361

Astle, B. J. (2008). Building and sustaining partnerships in higher education in nursing [Unpublished doctoral dissertation]. University of Alberta.

Aziato, L., \& Kwashie, A. (2014). Footprints of the nursing profession: Current trends and emerging issues in Ghana. African Books Collective.

Bedenlier, S., \& Zawacki-Richter, O. (2012). Internationalization of higher education and the impacts on academic faculty members. Research in Comparative \& International Education, 10(2), 185-201. https://doi.org/10.1177/1745499915571707

Bevis, O., \& Watson, J. (1989). Toward a caring curriculum: A new pedagogy for nursing (1st ed.). National League for Nursing.

Donato, E., Lightfoot, N., Carter, L., \& MacEwan, L. (2016). Inter-professional education in Canadian nursing programs and implications for continuing education. Journal of Professional, Continuing, and Online Education, 1(1), 1-12. https://journals.library.ualberta.ca/jpcoe/index.php/jpcoe/article/view/8/2

Donkor, N. T., \& Andrews, L. D. (2011). 21st century nursing practice in Ghana: Challenges and opportunities. International Nursing Review, 58(2), 218-224. https://doi.org/10.1111/j.1466-7657.2010.00856.x

Ergin, E., \& Akin, B. (2017). Globalization and its reflections for health and nursing. International Journal of Caring Sciences, 10(1), 607. ProQuest Document ID 1896832967. https://search.proquest.com/docview/1896832967

Fox, P., \& Hundley, S. (2011). The importance of globalization in higher education, new knowledge in a new era of globalization. In Tech.

Garone, A., \& Van de Craen, P. (2017). The role of language skills and internationalization in nursing degree programmes: A literature review. Nurse Education Today, 49, 140-144. https://doi.org/10.1016/j.nedt.2016.11.012 
Hazelkorn, E. (2009). Impact of global rankings on higher education research and the production of knowledge (Document code: ED.2009/WS/21). UNESCO Forum on Higher Education, Research and Knowledge. https://unesdoc.unesco.org/ark:/48223/pf0000181653

Holmes, D., Zayas, L., \& Koyfman, A. (2012). Student objectives and learning experiences in a global health elective. Journal of Community Health, 37(5), 927-934. https://doi.org/10.1007/s10900-012-9547-y

Huisman-de Waal, G., Feo, R., Vermeulen, H., \& Heinen, M. (2018). Students' perspectives on basic nursing care education. Journal of Clinical Nursing, 27(11-12), 2450-2459. https://doi.org/10.1111/jocn.14278

Jibeen, T., \& Khan, M. A. (2015). Internationalization of higher education: Potential benefits and costs. International Journal of Evaluation and Research in Education, 4(4), 196-199. https://doi.org/10.11591/ijere.v4i4.4511

Kelleher, S. (2013). Perceived benefits of study abroad programs for nursing students: An integrative review. The Journal of Nursing Education, 52(12), 690. https://doi.org/10.3928/01484834-20131118-01

Kisseih, D. A. N. (1962). Brief survey of nursing in Ghana. Ghana Medical Journal. http://www.ghanamedj.org/archives/GMJ\%201962\%20Vol\%201\%20No\%201/Nursing\% 20in\%20Ghana.pdf

Knight, J. (2004). Internationalization remodeled: Definition, approaches, and rationales. Journal of Studies in International Education, 8(1), 5-31. https://doi.org/10.1177/1028315303260832

Lippke, L. (2020). Government of Barbados expresses satisfaction with quality of African nurses. Briefly. https://briefly.co.za/81813-government-barbados-express-happinessghanaian-nurses-work.html

Lu, Y., \& Hou, F. (2015). International students who become permanent residents in Canada. Insights on Canadian Society, 1-10. Statistics Canada. https://www150.statcan.gc.ca/n1/en/pub/75-006-x/2015001/article/14299-eng.pdf

Mlambo, V. H., Ogunnubi, O., \& Mlambo, D. N. (2020). Student mobility, brain drain and the internationalisation of higher education in southern Africa. African Journal of Development Studies, 10(2), 59-82. https://doi.org/10.31920/2634-3649/2020/10n2a3

Myrick, F. (2004). Pedagogical Integrity in the knowledge economy. Nursing Philosophy, 5(1), 23-29. https://doi.org/10.1111/j.1466-769X.2004.00164.x

Nguyen, D., Vickers, M., Ly, T., \& Tran, M. (2016). Internationalizing higher education (HE) in Vietnam: Insights from higher education leaders-An exploratory study. Education + Training, 58(2), 193-208. https://doi.org/10.1108/ET-08-2015-0072

Nursing and Midwifery Council of Ghana. (2018). List of approved institutions and programs. https://www.nmcgh.org/t3f/phocadownload/March\%202018\%20List\%20of\%20\%20accr edited\%20institutions.pdf 
Ogilvie, L., Allen, M., Laryea, J., \& Opare, M. (2003). Building capacity through a collaborative international nursing project. Journal of Nursing Scholarship, 35(2), 113Retrieved from 118. https://doi.org/10.1111/j.1547-5069.2003.00113.x

Ogilvie, L., Opare, M., \& Allen, M. (2005). Graduate nursing education in Ghana, UPCD TIER 2 final report Unpublished manuscript].

Opare, M., \& Mill, J. E. (2000). The evolution of nursing education in a post-independence Context - Ghana from 1957 to 1970. Western Journal of Nursing Research, 22(8), 936944. https://doi.org/10.1177/01939450022044890

Quartey, P., \& Kwakye, E. (2009). The net benefit of migration: the case of migrant nurses from Ghana to the United Kingdom. Ghana Social Science Journal, 5(6), 62-63. http://ugspace.ug.edu.gh/handle/123456789/35039

School of Nursing and Midwifery. (n.d.-a). Admissions. University of Ghana. https://nursing.ug.edu.gh/admissions

School of Nursing and Midwifery. (n.d.-b). Mission and vision. University of Ghana. http://nursing.ug.edu.gh/about/mission_and_vision

Viken, B., Solum, E. M., \& Lyberg, A. (2018). Foreign educated nurses' work experiences and patient safety: A systematic review of qualitative studies. Nursing Open, 5(4), 455-468. https://doi.org/10.1002/nop2.146

Weberg, D., \& Weberg, K. (2014). Seven behaviors to advance teamwork: Findings from a study of innovation leadership in a simulation center. Nursing Administration Quarterly, 38(3), 230-237. https://doi.org/10.1097/NAQ.0000000000000041

Wilson, L., Harper, D. C., Tami-Maury, I., Zarate, R., Salas, S., Farley, J., Warren, N., Mendes, I., \& Ventura, C. (2012). Global health competencies for nurses in the Americas. Journal of Professional Nursing, 28(4), 213-222. https://doi.org/10.1016/j.profnurs.2011.11.021

Wit, H. D., \& Hunter, F. (2014). Europe's 25 years of internationalization. International Higher Education, 74, 14-15. https://doi.org/10.6017/ihe.2014.74.5467

World Health Organization. (2010). WHO global code of practice on the international recruitment of health personnel. https://www.who.int/hrh/migration/code/code_en.pdf 